\title{
Respon Beberapa Varietas Padi Terhadap Serangan Fusarium fujikuroi Penyebab Penyakit Bakanae
}

\section{Response of Some Rice Varieties Against Fusarium fujikuroi Causes of Bakanae Disease}

\author{
Darnetty, Eri Sulyanti \\ Jurusan Hama dan Penyakit Tumbuhan Fakultas Pertanian Universitas Andalas Padang \\ Email : darnetty_06@yahoo.com
}

\begin{abstract}
Fusarium fujikuroi is the cause of bakanae disease in rice plants. Level of bakanae disease attack on some rice cultivation land in West Sumatra, especially in Padang Pariaman district is quite high. One effort to suppress the development of $F$. fujikuroi is by planting resistant varieties. In this study, 15 rice varieties originating Sumatera Barat were used to be tested for their response to F. fujikuroi attack. The purpose of this study was to obtain the varieties with the low attack rate of $F$. fujikuroi. Parameters observed were number of dead seeds, number of dead seedlings, number of stunted seedlings, number of seeds showing symptoms of Bakanae and total infected seeds. The results of the study indicated that symptoms of $F$. fujikuroi attack varied which were dead seeds, stunting seedlings, dead seedslings and bakanae. The response of rice varieties to $F$. fujikuroi attack was different with characterized by different levels of infection rates. Low infection rates were found in Pessel varieties (2.0\%), Batang sahalai (15.5\%), Cisokan (17.0\%), and Batang Lembang (20\%). Other varieties showed a high percentage of $F$. fujikuroi attacks ranging from $20 \%$ to $54.5 \%$.
\end{abstract}

Keywords: rice, Bakanae, Fusarium fujikuroi

\section{PENDAHULUAN}

Beras merupakan salah satu makanan pokok yang paling disukai dan lebih dari $90 \%$ beras dunia dihasilkan dan dikonsumsi di negara-negara Asia (Singh et al. 2013). Salah satu penyakit yang sering ditemukan pada pertanaman padi adalah penyakit Bakanae. Penyakit Bakanae pertama kali ditemukan di Jepang pada tahun 1828 dan diberi nama pada tahun 1898 (Naeem et al, 2016). Bakanae merupakan salah satu penyakit penting pada tanaman padi yang telah menyebar luas pada banyak daerah pertanaman padi di Asia Tenggara, Afrika, Amerika dan Eropa (Desjardins et al. 2000, Khokhar \& Jaffrey, 2002).

Bakanae berasal dari bahasa Jepang yang berarti "foolish seedling" yang menunjukkan ada perpanjangan yang abnormal yang sering terlihat pada tanaman padi yang terinfeksi dan merupakan ciri khas dari serangan Fusarium fujikuroi (Webster \& Gunnell,1992). Pada awalnya penyebab bakanae di Jepang diidentifikasi sebagai jamur Fusarium moniliforme Sheldon dan kemudian diidentifikasi sebagai Fusarium fujikuroi Nirenberg dengan bentuk sempurnanya Gibberella fujikuroi (Gupta at al. 2015).

Kehilangan hasil akibat penyakit bakanae berkisar antara 3,0-95,4\%, tergantung pada daerah dan varietas yang ditanam (Ou, 1985; Hajra et al. 1994; Singh \& Sunder, 2012). Di India, insidensi penyakit bakanae selalu meningkat dan kehilangan hasil pada beberapa daerah seperti Assam, Andhra Pradesh, Tamilnadu, Haryana and Punjab berkisar $15-25 \%$ (Rathaiah et al. 1991; Sunder et al. 1988; Pannu et al. 2012). Penyakit ini merupakan masalah serius di negara-negara seperti, Jepang, Taiwan, Thailand, Turki, Amerika 
Serikat dan Filipina (Webster \& Gunnell, 1992).

Di Indonesia penyakit bakanae ini belum begitu banyak mendapat perhatian, kemungkinan karena penyakit ini relatif baru dan tingkat serangan yang masih rendah sehingga kehilangan hasil belum dianggap berarti secara ekonomi, namun penyakit ini perlu diwaspadai sebelum berkembang sebagai penyakit penting pada tanaman padi seperti di Jepang, India dan Thailand. Darnetty dan Sulyanti (2014) melaporkan bahwa penyakit bakanae telah ditemukan pada pertanaman padi di Sumatara Barat khususnya di dataran rendah (Kota Padang) tingkat serangannya pada beberapa lahan relatif tinggi atau sudah mencapai 20\%. Di Kalimantan Selatan juga pernah dilaporkan bahwa penyakit bakanae telah menyebar luas pada varietas IR 42 di musim tanam 1989/1990 dengan kehilangan hasil diperkirakan sekitar 25\% (Prajudin, 1994).

Penularan penyakit bakanae dapat melalui benih dan juga melalui tanah, namun yang paling utama melalui benih (Naeem et al. 2016; Semangun, 2005). Bibit yang terinfeksi di lapangan kelihatan lebih tinggi dari bibit normal dengan daun yang kekuningan, dan ada yang mati sebelum dipindahkan ke lapangan. Bibit terinfeksi yang bertahan sampai dilapangan akan memanjang, dan membentuk bulir lebih awal namum hampa (Ou, 1985). Benih yang terinfeksi berat akan mati sebelum dipindahkan ke lapangan, dan yang masih bertahan hidup bisa mati setelah pindah ke lapangan.

Berbagai metoda pengendalian telah dilakukan termasuk penggunaan varietas tahan, secara kultur teknis, secara hayati dan secara kimia (Sharma \& Bagga 2007; Singh et al., 2013), namun cara pengendalian yang paling umum dilakukan adalah dengan penggunaan fungisida yang diketahui berbahaya bagi kesehatan dan bahkan untuk mikroorgansme yang menguntungkan (Naeem et al. 2016). Mengingat di Sumatera Barat banyak varietas padi yang tersedia maka ini merupakan suatu peluang untuk mendapatkan varietas yang tahan terhadap serangan G. fujikuroi. Sejauh ini penelitian tentang penyakit bakanae secara umum belum banyak dilakukan. Oleh karena itu penelitian in bertujuan untuk mendapatkan varietas yang tahan terhadap serangan $F$. fujikuroi

\section{METODE PENELITIAN}

\section{Tempat}

Penelitian ini telah dilaksanakan di Laboratorium Fitopatologi dan di Rumah Kawat Fakultas Pertanian Universitas Andalas

\section{Metode Penelitian}

Benih yang digunakan dalam penelitian ini adalah benih sehat sebanyak 15 varietas (Batang Piaman, Batang Sahalai, Batang Lembang, Cisokan, Cintaku, IR 42, IR 66, Kuniang Sarai, Kuniang Solok, Kuriak Kusuik, Padi Putiah, Pessel, Sarai Rarumpun, Sari Dewi dan Suntiang Anak Daro) yang ada di Sumatera Barat. Semua benih ini diperoleh dari Prof. Dr. Ir. Irfan Suliansyah, MS dan Dr. Ir. Etti Swasti, MS..

\section{Pelaksanaan Penelitian}

Isolat jamur Fusarium fujikuroi berasal dari akar tanaman padi yang memperlihatkan gejala penyakit Bakanae di areal pertanaman padi di kota Padang.. Akar padi tersebut dicuci, dipotong-potong dengan ukuran $1 \mathrm{~cm} \times 1 \mathrm{~cm}$ dan disterilisasi permukaan dengan natrium hipoklorit $2 \%$ selama 5 menit. Selanjutnya potongan akar tersebut ditumbuhkan dalam medium spesifik untuk Fusarium, Pentaclorobenzene Pepton Agar (PPA) dan diinkubasi selama 4 hari. Jamur yang tumbuh dipindahkan ke medium Water Agar (WA) dengan cara menggoreskan suspensi konidianya dengan kerapatan (1-9 konidia per bidang pandang). Pada hari kedua, spora tunggal yang sudah mulai berkecambah pada medium WA dipindahkan ke medium Potato Dextose Agar (PDA) sehingga didapat biakkan murni yang berasal dari spora tungal.

Pembuatan suspensi konidia jamur dilakukan dengan cara membiakkan isolat G. fujikuroi pada Erlenmeyer $(250 \mathrm{ml})$ yang berisi $30 \mathrm{ml}$ PDA, dan pada hari ke 5 ditambahkan akuades steril sebanyak $20 \mathrm{ml}$ dan digoyang-goyang agar konidianya terlepas. Selanjutnya dihitung jumlah 
konidia dengan menggunakan hemositometer dan selanjutnya dibuat suspensi konidia dengan kerapatan $10^{6} / \mathrm{ml}$ dengan metoda pengenceran.

Benih diinokulasi dengan cara merendam benih tersebut dengan suspensi konidia jamur $\left(10^{6} / \mathrm{ml}\right)$ selama 30 menit, lalu dikering anginkan. Selanjutnya benih disemaikan dalam pot plastik (dia. $35 \mathrm{~cm}$ ) berisi $5 \mathrm{~kg}$ campuran tanah dan pupuk kandang dengan perbandingan volume $(1: 1)$.

\section{Pengamatan}

Pengamatan dilakukan pada umur 30 hari setelah semai. Parameter yang diamati meliputi jumlah benih yang mati, bibit yang mati, bibit yang stunting, bibit memperlihatkan gejala bakanae dan total infeksi

\section{HASIL DAN PEMBAHASAN}

\section{A. Hasil}

Semua varietas padi yang diuji terinfeksi oleh $F$. fujikuroi dengan gejala dan tingkat serangan yang bervariasi (Tabel 1 dan Gambar 1). Gejala serangan F. fujikuroi tertinggi berupa bibit menguning dengan tingkat serangan rata-rata $20,56 \%$ dan diikuti oleh bibit memanjang (bakanae) $5.83 \%$, benih mati $4.3 \%$, bibit mati $3,23 \%$, bibit stunting $2.03 \%$. Tidak semua varietas memperlihatkan semua jenis gejala. Tujuh varietas (Batang lembang, Batang Piaman, Banang Sahalai, IR 42, IR 66, Padi Putiah dan Sunting Anak Daro) memperlihatkan semua gejala, sedangan varietas lainnya seperti Cisokan tidak memperlihatkan gejala bibit mati, dan stuning; Cintaku tidak memperlihatkan gejala Bakanae; Kuniang Sarai, Kuniang Solok dan Kuriak Kusuik tidak memperlihatkan gejala benih mati; Pessel tidak memperlihatkan gejala benih mati, bibit mati, stunting dan bakanae; Sarai tidak memperlihatkan gejala benih mati, dan stunting dan Sari Dewi tidak memperlihatkan gejala stunting.

Total bibit terinfeksi dari masingmasing varietas bervariasi berkisar antara 2 - 54.5\% dengan rata-rata $35.9 \%$. Dari 15 varietas padi yang diuji ada beberapa varietas yang tingkat infeksinya relatif rendah yaitu varietas Pessel $(2 \%)$, Banang Sahalai (15.5\%), dan Cisokan (17\%) dan Batang lembang (20\%)., sedangkan varietas

Tabel 1: Persentase bibit yang terinfeksi oleh G. fujikuroi dengan berbagai gejala pada 15 varietas padi (umur 30 hari setelah semai)

\begin{tabular}{|c|c|c|c|c|c|c|c|c|c|c|c|}
\hline \multirow{2}{*}{$\begin{array}{c}\text { Varietas } \\
\text { Batang Lembang }\end{array}$} & \multicolumn{2}{|c|}{$\begin{array}{c}\text { Benih } \\
\text { mati } \\
(\%)\end{array}$} & \multicolumn{2}{|c|}{$\begin{array}{l}\text { Bibit } \\
\text { mati } \\
(\%)\end{array}$} & \multicolumn{2}{|c|}{$\begin{array}{c}\text { Bibit } \\
\text { Stunting } \\
(\%)\end{array}$} & \multicolumn{2}{|c|}{$\begin{array}{c}\text { Bibit } \\
\text { menguning } \\
(\%)\end{array}$} & \multicolumn{2}{|c|}{$\begin{array}{c}\text { Gejala } \\
\text { Bakanae } \\
(\%)\end{array}$} & $\begin{array}{c}\text { Total } \\
\text { bibit } \\
\text { terinfeksi } \\
(\%) \\
\end{array}$ \\
\hline & 0.5 & $\mathrm{e}$ & 4.5 & $\mathrm{~b}$ & 4.5 & $\mathrm{ab}$ & 2.5 & $\mathrm{~g}$ & 8.0 & bcd & $20.0 \mathrm{fg}$ \\
\hline Batang Piaman & 19.0 & $\mathrm{~b}$ & 9.5 & $\mathrm{a}$ & 5.5 & $\mathrm{a}$ & 8.5 & $\mathrm{f}$ & 6.5 & def & $49.0 \mathrm{bc}$ \\
\hline Banang Sahalai & 0.5 & $\mathrm{e}$ & 2.0 & $\mathrm{~d}$ & 0.5 & de & 12.0 & ef & 0.5 & $\mathrm{~h}$ & $15.5 \mathrm{~g}$ \\
\hline Cisokan & 4.5 & $\mathrm{~d}$ & 0.0 & $\mathrm{e}$ & 0.0 & $\mathrm{e}$ & 7.5 & $\mathrm{f}$ & 5.0 & $\mathrm{fg}$ & $17.0 \mathrm{fg}$ \\
\hline Cintaku & 9.5 & $\mathrm{c}$ & 4.0 & $\mathrm{bc}$ & 3.5 & $\mathrm{bc}$ & 21.0 & $\mathrm{~d}$ & 0.0 & $\mathrm{~h}$ & $38.0 \mathrm{de}$ \\
\hline IR 42 & 0.5 & $\mathrm{e}$ & 0.5 & de & 4.5 & $a b$ & 41.0 & $\mathrm{~b}$ & 6.0 & efg & $52.5 \mathrm{~b}$ \\
\hline IR 66 & 0.5 & $\mathrm{e}$ & 2.5 & $\mathrm{c}$ & 2.0 & cde & 15.0 & $\mathrm{e}$ & 4.5 & $\mathrm{~g}$ & $24.5 \mathrm{f}$ \\
\hline Kuniang Sarai & 0.0 & $\mathrm{e}$ & 0.5 & de & 0.5 & de & 34.0 & $\mathrm{c}$ & 6.5 & def & $41.5 \mathrm{de}$ \\
\hline Kuniang Solok & 0.0 & $\mathrm{e}$ & 2.5 & $\mathrm{c}$ & 0.5 & de & 34.5 & $\mathrm{c}$ & 6.0 & efg & 42.5 cde \\
\hline Kuriak Kusuik & 0.0 & $\mathrm{e}$ & 4.5 & $\mathrm{~b}$ & 0.5 & de & 30.5 & $\mathrm{c}$ & 8.0 & bcd & $43.5 \mathrm{~cd}$ \\
\hline Padi Putiah & 22.5 & $\mathrm{a}$ & 9.0 & $\mathrm{a}$ & 2.5 & $\mathrm{~cd}$ & 10.0 & ef & 9.0 & $\mathrm{~b}$ & $53.0 \mathrm{~b}$ \\
\hline Pessel & 0.0 & $\mathrm{e}$ & 0.5 & de & 1.5 & de & 0.0 & $\mathrm{f}$ & 0.0 & $\mathrm{~h}$ & $2.0 \mathrm{~h}$ \\
\hline Sarai Sarumpun & 0.0 & $\mathrm{e}$ & 0.5 & de & 0.0 & $\mathrm{e}$ & 47.0 & $\mathrm{a}$ & 7.0 & cde & $54.5 \mathrm{a}$ \\
\hline Sari Dewi & 2.0 & de & 2.5 & $\mathrm{c}$ & 0.0 & $\mathrm{e}$ & 33.0 & $\mathrm{c}$ & 2.0 & $\mathrm{a}$ & $49.5 \mathrm{bc}$ \\
\hline Suntiang Anak Daro & 5.0 & d & 5.5 & $\mathrm{~b}$ & 4.5 & $a b$ & 12.0 & ef & 8.5 & $\mathrm{bc}$ & $35.5 \mathrm{e}$ \\
\hline Rata-rata & $4,3 \%$ & & $3,23 \%$ & & 2.03 & & 20.56 & & 5,8 & $3 \%$ & $35,9 \%$ \\
\hline
\end{tabular}

Angka pada kolom yang sama yang diikuti oleh huruf kecil yang sama berbeda tidak nyata pada taraf nyata 5\% menurut DNMRT 


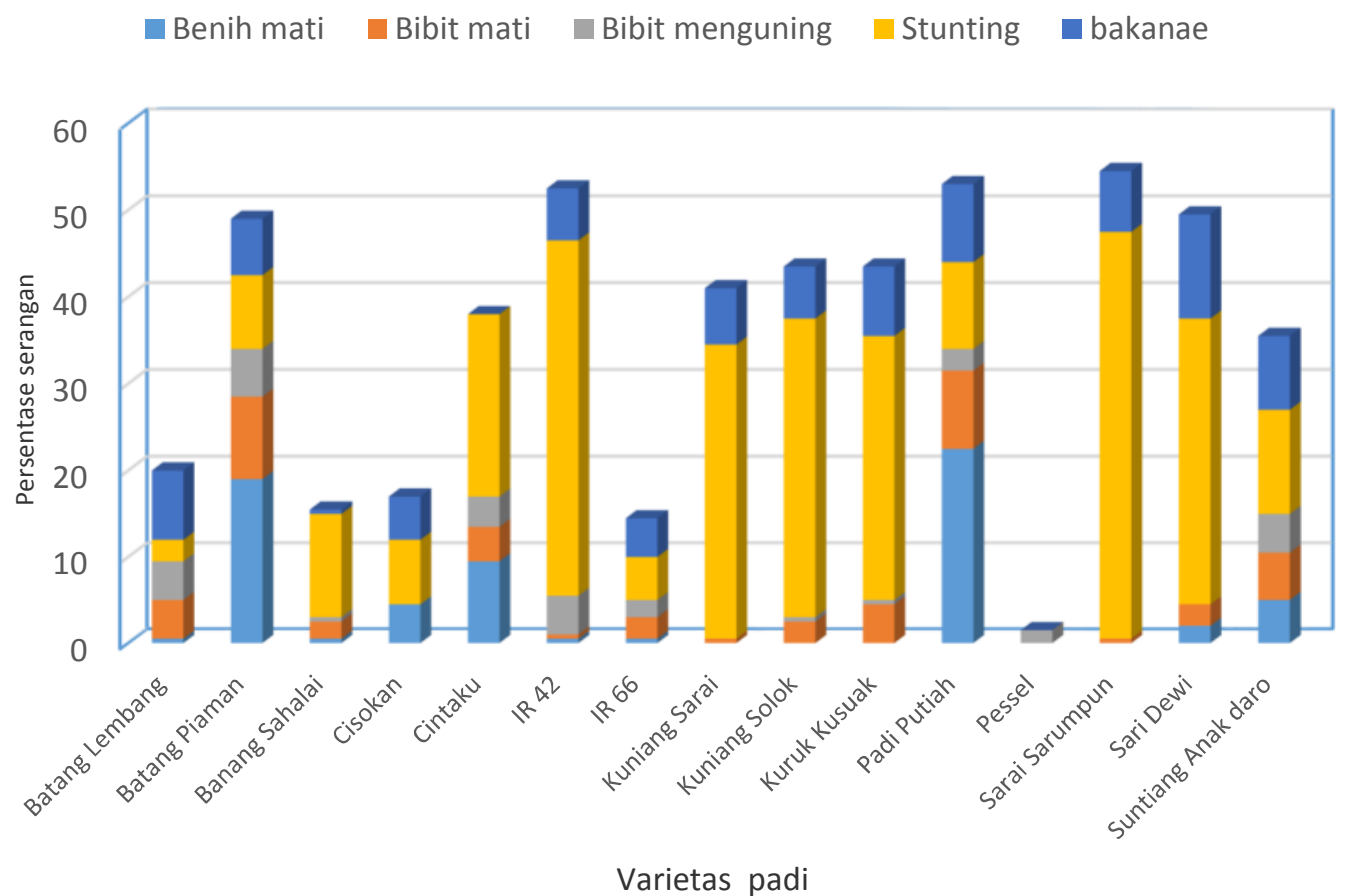

\section{Gambar 1. Persentase serangan $F$. fujikuroi pada 15 varietas padi}

lainnya dengan tingkat infeksi yang tinggi diatas $20 \%$ yaitu varietas Sarai Sarumpun (54,5\%), Padi Putiah (53\%), IR 42 (52.5\%), Sari Dewi (49,5\%), Batang Piaman (49\%), Kuriak Kusuik (43.5\%), Kuniang Solok $(42.5 \%)$, Kuniang Sarai (41.5), Cintaku (38\%), Suntiang Anak Daro (35.5\%), dan IR $66(24,5 \%)$.

\section{Pembahasan}

Terserangnya semua varietas padi menunjukkan bahwa tidak ada varietas padi yang betul-betul tahan terhadap F. fujikuroi. Infeksi akibat serangan $F$. Fujikuroi tidak hanya menimbulkan gejala bakanae saja tetapi juga gejala lain seperti benih mati, bibit mati, bibit menguning dan bibit stunting. Muculnya beragam gejala ini disebabkan $F$. fujikuroi tidak hanya menghasilkan senyawa gibberalin tetapi juga asam fusarik. Menurut Booth (1971), Nyvall, (1999), dan Semangun (2005), bahwa asam fusarik yang menyebabkan stunting atau matinya tanaman dan gibberallin menyebabkan pertumbuhan yang memanjang (bakanae) pada padi. Selanjutnya Sharma \& Bagga (2007); Amtaulli et al., (2010); Kaur et al., (2014) menyatakan bahwa keragaman yang berarti terlihat pada perkembangan gejala dan pembentukan gibberalin dan asam fusarik. Perkembangan gejala sangat dipengaruhi oleh jumlah inokulum, perbedaan isolat patogen, kondisi nutrisi, produksi gibberalin dan asam fusarik.

Perbedaan tingkat infeksi oleh serangan G. fujikuroi disebabkan oleh perbedaan varietas yang menyebabkan perbedaan ketahanan. Menurut Agrios (2005) bahwa keragaman tingkat ketahanan varieatas tanaman terhadap suatu patogen mungkin disebabkan oleh perbedaan jenis dan jumlah gen tahan yang ada pada setiap varietas tersebut.

\section{KESIMPULAN}

Masing-masing varietas padi yang diuji memperlihatkan respon yang berbeda terhadap serangan $F$. fujikuroi. Infeksi akibat serangan $F$. fujikuroi pada tanaman padi ditunjukkan dengan beberapa gejala yaitu benih mati, bibit mati, bibit menguning, bibit stunting dan bibit memanjang yang lebih dikenal dengan bakanae. Dari 15 varietas yang diuji ada 
beberapa varietas yang total infeksinya relatif rendah yaitu: varietas Pessel $(2,0 \%)$, Banang Sahalai (15.5\%) dan Cisokan $(17,0 \%)$, dengan gejala bakanae secara berurutan $0,0,5$ dan $5 \%$, sedangkan varietas lainnya memperlihatkan persentase serangan $F$. fujikuroi cukup tinggi berkisar antara $20 \%$ sampai $54.5 \%$.

\section{UCAPAN TERIMA KASIH}

Terima kasih kepada Kementerian Riset, Teknologi dan Pendidikan Tinggi yang telah mendanai penelitian ini

\section{DAFTAR PUSTAKA}

Agrios GN. 2005. Plant Pathology. Fifth Edition. Academic Press. Boston, London, New York, Oxford

Amatulli MT, D Spadaro, ML Gullino \& A Garibaldi. 2010. Molecular identification of Fusarium spp. associated with bakanae disease of rice in Italy and assessment of their pathogenicity. Plant. Pathol. 59: 839-844.

Booth C. 1971. The genus Fusarium. Commonwealth Mycological Institute, Kew, Surrey, England (UK).

Darnetty, E Sulyanti. 2014. Distribusi dan mating populasi (MPs) Fusarium yang berasosasi dengan penyakit bakanae pada tanaman padi di Sumatera Barat. Prosiding Seminar Nasional dan Rapat Tahunan Dekan Bidang Ilmu Pertanian BKS-PTN Barat di Universitas Lampung, 1921 Agustus 2014.

Desjardins AE, HK Mananhar, CM Maragos. 2000. Fusarium species from Nepalese rice and production of mycotoxins and gibberellic acid by selected species. Appl. Environ. Microbiol 66(3): 1020-1025

Gupta AK, IS Solanki, BM Bashyal, Y Singh, K Srivastava. 2015. Bakanae of rice- an emerging disease in Asia. The Journal of Animal and Plant Sciences, 25(6): 1499-1514
Hajra KK, LK Ganguly, DC Khatua. 1994. Bakanae disease of rice in the West Bengal. J. Mycopath. Res. 32(2): 9599.

Kaur J, PPS Pannu, S Sharma. 2014. Morphological, biochemical and molecular characterization of Gibberella fujikuroi isolates causing bakanae disease of Basmati rice. $J$. Mycol. Plant Pathol. 44: 78-82.

Khokhar LK., AH Jaffrey. 2002. Identification of sources of resistance against bakanae and foot rot disease of rice. Pakistan Journal of Agricultural Research 17:176177

Naeem M, M Iqbal, N Parveen, Sami-UlAllh, Q Abbas, A Rehman, MS Shauket. 2016. An Over view of bakanae disease of rice. AmericanEurasian J. Agric. and Environ Sci. 16 (2): 270-277.

Nyvall RF 1999. Field crop diseases. Iowa State University Press, USA.

Ou SH. 1985. Rice disease. Commonwealth Mycological Institue, Kew, England.

Pannu PPS, J. Kaur, G. Singh, J. Kaur. 2012. Survival of Fusarium moniliforme causing foot rot of rice and its virulence on different genotypes of rice and basmati rice. Ind. Phytopath. 65S: 149-209.

Prajudin B. Penyakit bakanae pada padi di Kalimantan Selatan 1994. Buletin Penelitian KINDAI 5(2):

Rathaiah Y, GR Das, KHU Singh. 1991. Estimation of yield loss and chemical control of bakanae disease of rice. Oryza. 28: 509-512.

Semangun H. 2005. Penyakit-penyakit Tanaman Pangan di Indonesia. Gajah Mada University Press.

Sharma VK, PS Bagga. 2007. Pathogenic behaviour of Fusarium moniliforme isolates causing foot rot disease in Basmati rice. Plant Dis. Res. 22: 165-166. 
Singh AK, MK Meena, RC Bharati, RM Gade. 2013. Effect of Sulphur and Zinc Management on Yield, Nutrient Uptake, Changes in Soil Fertility and Economics in Rice (Oryza sativa)-lentil (Lens culinaris) Cropping System. Indian J. Agril. Sci. 83 (3):344-348.

Singh R., S Sunder. 2012. Foot rot and bakanae of rice: an overview. Rev. Plant. Pathol. 5: 566-604.
Sunder S, Satyavir., A. Singh. 1988. Screening of rice genotypes for resistance to bakanae disease. Ind. Phytopath. 51: 299-300.

Webster RK, PS Gunnell. 1992. Compendium of rice disease. First edition, The American Phytopathological Society Press. St. Paul, Minnesota, USA. 